\title{
Caracterização da textura das raízes de mandioca in natura e cozidas e analise da composição centesimal.
}

Laís Maciel Rodrigues ${ }^{1}$; Renato Souza $\mathrm{Cruz}^{2}$; Geany Peruch Camilloto ${ }^{3}$

1. Bolsista PIBIC/CNPq, Graduando em Engenharia de Alimentos, Universidade Estadual de Feira de Santana, email: sialmaciel@gmail.com;

2. Orientador, Departamento de Tecnologia, Universidade Estadual de Feira de Santana, e-mail: cruz.rs@uefs.br;

3. Participante do projeto, Departamento de Tecnologia, Universidade Estadual de Feira de Santana, e-mail: geanyperuch@yahoo.com.br.

PALAVRAS-CHAVE: mandioca, cozimento, tecnologia.

\section{INTRODUÇÃO}

A mandioca (Manihot esculenta Crantz) é uma espécie de grande relevância agronômica adaptada às condições edafo-climáticas brasileiras, tolerante a estresses bióticos e abióticos, podendo apresentar rendimentos elevados até mesmo em solos já esgotados por outras culturas (GRIZOTTO, 2001). As raízes das variedades de mandioca de mesa destinadas à comercialização devem atender às exigências sensoriais e tecnológicas do consumidor, demonstrando sabor característico, textura macia e cozimento rápido (FIGUEIREDO, 2012; MEZETTE et al., 2009). Diante disso, os pesquisadores tem como objetivo analisar a composição química de diferentes espécies de mandioca e suas relações com o tempo de cocção e a qualidade da massa de suas raízes.

\section{MATERIAL E MÉTODOS OU METODOLOGIA (ou equivalente) Preparo da amostra}

As raízes de mandioca foram fornecidas pela EMBRAPA Mandioca e Fruticultura e preparadas para análise no mesmo dia. Para cada repetição, foram colhidas todas as raízes comerciais (padrão aipim) de 8 plantas de mandioca. As raízes selecionadas foram lavadas, secas, picadas em cilindros, descascadas, divididas ao meio no sentido do comprimento e ao quarto.

\section{$\underline{\text { Tempo de coccão das raízes }}$}

Para essa avaliação foi utilizado o aparelho Mattson modificado adaptado por Feniman (2004). Cilindros da parte central com pesos de 60 a 70 g de 12 raízes foram utilizados para determinar o tempo de cozimento. O aparelho foi imerso com as amostras em panela de aço inoxidável contendo água destilada em ebulição. Sobre cada cilindro de raiz de mandioca a ponta de uma agulha foi colocada com peso total de 90,0 g, fixada em uma haste de vidro. Foi considerado o tempo de cozimento aquele em que a sétima agulha (metade mais uma) desça $2 \mathrm{~cm}$ dentro da amostra. $\mathrm{O}$ tempo máximo que as raízes permaneceram na água em ebulição foram de 40 minutos.

\section{Lipídios}

A determinação de lipídios foi realizada através do método de Bligh e Dyer, um método para extrair gordura a frio que utiliza uma mistura de três solventes: Clorofórmio, Metanol e Água. (Cecchi, 2003). Os resultados foram expressos em porcentagem.

\section{Fibra alimentar}


Para determinação do teor de fibra alimentar foi utilizado o método enzimáticogravimétrico com tratamento enzimático com tampão fosfato de acordo com metodologia descrita Instituto Adolf Lutz (2005).

\section{$\underline{\text { Textura das raízes cozidas quanto à resistência ao cisalhamento }}$}

Cilindros da parte central com pesos de 60 a 70 g de 5 raízes de cada clone foram cozidos durante o tempo ótimo de cozimento e a análise foi realizada em texturômetro segundo Talma et al. (2013). A determinação da resistência ao corte foi realizada em pedaços de $3 \mathrm{~cm}$ de comprimento, cortados ao meio no sentido longitudinal, de raízes de mandioca, das polpas cruas e cozidas. Foi utilizado texturômetro TA.XT Plus Texture Analyser do Laboratório de Panificação da Universidade Estadual de Feira de Santana.

\section{RESULTADOS E/OU DISCUSSÃO (ou Análise e discussão dos resultados) Tempo de Coccão das Raízes}

O tempo de cocção de 08 variedades/ clones de raízes de mandioca foi determinado segundo metodologia descrita e os resultados estão disposta na tabela abaixo.

De acordo com o tempo de cozimento, as raízes foram classificadas como: bom (11 a 20 minutos), regular (21 a 30 minutos) e ruim (maior que 30 minutos). Somente a variedade Eucalipto foi classificada como "bom"; o Aimpim Brasil foi classificada como "regular" e as demais variedades como "ruim". As variedades de Híbrido não alcançaram o cozimento desejado e o tempo de 50 minutos foi estabelecido como limite. Os principais componentes da mandioca, os carboidratos, são classificados como hidrocolóides e são substâncias capazes de reter água durante o processo de cocção. Cereda e Vilpoux (2003) sugeriram duas hipóteses para explicar o não cozimento da mandioca. A primeira é que a impermeabilização da parede celular impede a penetração da água nas células da raiz impedindo a gelificação do amido e hipótese, admite alterações na parede celular, que não se deforma, impedindo o inchamento dos grânulos de amido e consequentemente de uma boa gelificação, fator característico de um bom cozimento.

\section{Lipídios}

Os resultados demonstraram que não houve diferença significativa $(p>0,05)$ entre as amostras para o teor de lipídeo, sendo assim, o teor de lipídeo médio foi de 0,827 \pm 0,165. Lipídeos são compostos de carbono, hidrogênio e oxigênio encontrados em diversos alimentos na forma de gordura e/ou óleos.

\section{Fibra Alimentar Total (FAT)}

De acordo com os resultados obtidos a variedade que apresentou uma porcentagem de Fibras Alimentar Total (FAT) elevada entre às demais foi a variedade Híbrido-2009-0905 . 
Alguns autores afirmam que o teor de fibras nas raízes de mandioca poderá aumentar com a idade da planta (KATO, O. R.; CORRÊA, H.; SIQUEIRA, J. O., 1990) e/ou estar vinculado à especificidade da cultivar. Como as fibras referem-se ao total de polissacarídeos da planta, junto com a lignina, que são resistentes à hidrólise por enzimas digestivas do trato gastrintestinal, formadas por componentes majoritários, tais como a celulose, a hemicelulose, a pectina e a lignina, podemos classificar essa variedade como uma fonte superior de fibras dietéticas entre as demais variedades.

\section{Textura das raízes cozidas quanto à resistência ao cisalhamento}

Através dos resultados obtidos pode-se observar que o percentual de perda de firmeza com o cozimento das raízes foi significativo para as variedades Dourada e Eucalipto. Durante o processo de cocção, ambas as raízes apresentaram uma considerável absorção de água que dificultou na análise estrutural de suas raízes. O aumento da taxa de alteração dos parâmetros de textura durante os primeiros três minutos de cozedura devese à elevada percentagem de gelatinização (Beleia et al., 2005), que está associada com uma alta absorção de água (Linares et al., 2005) que produz hidrólise e solubilização de parede celular (Alvarez e Canet., 2001). Estes fenômenos resultam numa diminuição abrupta de rigidez, dureza e firmeza do tecido.

\section{CONSIDERAÇÕES FINAIS (ou Conclusão)}

A partir dos resultados obtidos foi possível concluir que a variedade Eucalipto foi classificada como "bom"; o Aipim Brasil foi classificada como "regular" e as demais variedades como "ruim", devido as suas composições e impermeabilização da parede celular.

Em relação à analise de fibras somente variedade Híbrido-2009-09-05 apresentou um teor de fibras mais elevado que as demais, podendo ser considerada uma variedade de com fonte superior de fibras dietéticas.

Em relação aos lipídios, os resultados demonstraram que não houve diferença significativa $(p>0,05)$ entre as amostras para o teor de lipídeo, sendo assim, o teor de lipídeo médio foi de $0,827 \pm 0,165$.

A análise de textura avaliou a firmeza das amostras das 08 variedades analisadas e através do percentual de perda de firmeza foi possível afirmar que ocorreu um decréscimo de perda significativa para as variedades Dourada e Eucalipto devido à pressão interna desenvolvida na célula como um resultado do inchaço do amido gelatinizado no processo de cocção.

\section{REFERÊNCIAS}


ALVAREZ, MD e W. CANET. Cinética de amolecimento térmico de tecido de batata por meio de métodos diferentes aquecida. Eur Food Res Technol, 212, 454-464, 2001.

BELEIA, A., BUTARELO, S. e R.S. SILVA. Modelagem de gelatinização do amido durante o cozimento da mandioca (Manihot esculenta Crantz). Ciência e Tecnologia de Alimentos, 2005.

CECCHI, Heloísa Máscia. Fundamentos Teóricos e Práticos em Análise de Alimentos, $2^{\mathrm{a}}$ Edição, Campinas, SP, Editora da UNICAMP, 2003.

CEREDA, M. P.; VILPOUX, O. F. Farinhas e derivados. In: CEREDA, M. P.; VILPOUX, O. F. (Coord.). Tecnologias, usos e pontencialidades de tuberosas amiláceas latinoamericanas. São Paulo: Fundação Cargill, 2003. p.576 -619. (Série Culturas de Tuberosas Amiláceas LatinoAmericanas, 3).

FENIMAN, C. M. Caracterização de raízes de mandioca (Manihot esculenta Crantz) do cultivar IAC 576-70 quanto à cocção, composição química e propriedades do amido em duas épocas de colheita. 2004. 99 f. Dissertação (Mestrado em Ciência e Tecnologia de Alimentos). Escola Superior de Agricultura "Luiz de Queiroz”, Universidade de São Paulo, Piracicaba.

FIGUEIREDO, P. G. Morfo-anatomia de raízes tuberosas de mandioca (Manihot esculenta Crantz) cultivar IAC 576-70 em diferentes preparos do solo. 2012. 73 f. Dissertação (Mestrado em Agronomia). Faculdade de Ciências Agronômicas, Universidade Estadual Paulista, Botucatu.

GRIZOTTO, R. K. Mandioca "Chips" Uma tecnologia para o aproveitamento da mandioca (Manihot esculenta Crantz). Campinas, 2000, 130 f. Tese (Doutorado em Tecnologia de Alimentos) - Faculdade de Engenharia de Alimentos, Universidade Estadual de Campinas.

INSTITUTO ADOLFO LUTZ. Métodos físico-químicos para análise de alimentos. 4 ed. Brasília, DF: Ministério da Saúde, 2005. 1018 p.

KATO, O. R.; CORRÊA, H.; SIQUEIRA, J. O. Efeito de micorrizas vesicular-arbusculares no crescimento da mandioca (Manihot esculenta Crantz) em solo adubado com doses crescentes de superfosfato triplo. Ciênc. Prat., v. 14, n. 1, p. 09-19, 1990.

LINARES, A., VERGARA, M., e S. HASE. Efeito do tempo de cozedura sobre as dimensões e propriedades de fatias de mandioca Cozinhar. X Congresso Argentino de Ciência e Tecnologia de 15,7 Livro de Resumos Food. Mar del Plata, Argentina, 18 de maio, 2005.

TALMA, S. V., ALMEIDA, S. B., LIMA, R. M. P., VIEIRA, H. D., BEBERT, P. A. Tempo de cozimento e textura de raízes de mandioca. Brazilian Journal of Food Technology, v. 16, n. 2, p. 133-138, 2013. 